Jurnal Keperawatan Silampari

Volume 4, Nomor 2, Juni 2021

e-ISSN: 2581-1975

p-ISSN: 2597-7482

DOI: https://doi.org/10.31539/jks.v4i2.1874

\title{
PERAWATAN DIRI IBU PRIMIPARA SELAMA PERIODE NIFAS
}

\author{
Jumiati Riskiyani Dwi Nandia ${ }^{1}$, Anggorowati ${ }^{2}$, Fatikhu Yatuni Asmara ${ }^{3}$ \\ Universitas Diponegoro, ${ }^{1,2,3}$ \\ riezky0501@ gmail.com ${ }^{1}$
}

\begin{abstract}
ABSTRAK
Penelitian ini bertujuan untuk mendeskripsikan bagaimana perawatan diri yang dilakukan oleh ibu primipara selama periode postpartum. Metode yang digunakan adalah studi literature review dengan mencari beberapa artikel dan jurnal melalui proses pencarian dari Pubmed, Proquest, Scopus Ebsco, dan Google scholar. Hasil penelitian menunjukkan bahwa masih banyak ibu primipara yang membutuhkan pendidikan perawatan diri untuk menjaga diri dan bayinya selama masa nifas. Perawatan diri pada setiap ibu primipara saat melahirkan sangat berbeda, salah satunya karena pengetahuan dan usia ibu. Ibu primipara lebih cenderung mencoba dan belajar memahami diri mereka sendiri dalam hal perawatan diri selama masa nifas daripada multipara yang telah memiliki pengalaman sebelumnya. Simpulan, sebagian besar ibu primipara masih kurang mampu melakukan perawatan diri dikarenakan ibu primipara belum berpengalaman merawat diri maupun bayinya, sehingga masih cenderung belajar dan berusaha lebih keras menyesuaikan kondisinya.
\end{abstract}

Kata Kunci: Kemandirian, Postpartum, Primipara

\section{ABSTRACT}

This study aims to describe how primiparous mothers perform self-care during the postpartum period. The method used is a literature review study by searching for several articles and journals through a search process from Pubmed, Proquest, Scopus Ebsco, and Google scholar. The results showed that many primiparous mothers needed self-care education to take care of themselves and their babies during the postpartum period. Self-care for each primiparous mother during childbirth is very different, one of which is due to the knowledge and age of the mother. Primiparous mothers are more likely to learn to understand themselves in terms of self-care during the puerperium than are multiparous who have had previous experiences. In conclusion, most primiparous mothers are still less able to do self-care because primiparous mothers have no experience caring for themselves and their babies, so they still tend to learn and try harder to adjust to their conditions.

Keywords: Independence, Postpartum, Primipara

\section{PENDAHULUAN}

Periode nifas menjadi suatu waktu yang berharga bagi ibu dalam kehidupannya. Setelah memasuki periode tersebut ibu akan banyak mengalami perubahan kondisi secara fisik maupun psikis. Perubahan fisik ibu selama masa nifas yang paling utama 
ialah pada organ reproduksinya. Ibu setelah melahirkan akan mengalami proses kembalinya rahim seperti kondisi sebelum hamil yang disebut involusi uteri.

Ibu nifas mulai dapat mengkondisikan dirinya sekitar satu minggu pertama nifas dan ibu mulai belajar mandiri menjalani aktivitasnya. Penyesuaian peran ibu tersebut dilalui dalam 3 fase yang meliputi fase taking-in, fase taking-hold dan fase letting go. Tahapan fase merupakan fase penting dalam proses perubahan psikis ibu dalam menjalani periode nifas. Periode nifas ini sangat dibutuhkan perawatan yang lebih ekstra pada ibu maupun bayinya (Khatun et al., 2018; Padila et al., 2018).

Berdasarkan Survey Demokrasi dan Kesehatan Indonesia, sebanyak 50\% kematian dialami oleh ibu yang terjadi sehari paska melahirkan, dan $60 \%$ terjadi setelah melahirkan (Kurniasari, 2019). Beberapa komplikasi fatal umumnya seringkali terjadi pada minggu pertama masa nifas seperti perdarahan, sepsis serta eklamsia (Yustiawan \& Nandini, 2018). Resiko komplikasi pada ibu nifas tersebut juga dapat dipengaruhi oleh beberapa faktor antara lain keadaan status gizi ibu selama masa kehamilan, keadaan sosial ekonomi, kondisi kesehatan saat hamil sampai pada saat kelahiran, serta yang paling utama ialah ketersediaan dan aksesibilitas ibu terhadap pelayanan kesehatan dalam memantau kondisi kesehatannya khususnya pada saat periode nifas (Indrayanti \& Hikmah, 2017). Di Indonesia jumlah Angka Kematian Ibu tergolong relatif tinggi dibanding dengan negara ASEAN lainnya seperti Singapura dan Malaysia dengan rentang 2-3 AKI per 100.000 kelahiran hidup. Angka Kematian Ibu sebagai salah satu indikator tingkat kesehatan perempuan serta mencerminkan resiko yang dihadapi setiap ibu selama kehamilan sampai dengan pasca persalinan (Wahyuni \& Nurlatifah, 2017).

Dalam meneliti hal ini peneliti menggunakan beberapa peneliti terdahulu diantaranya; pertama, karya Herlina, Vera Virgia, Riska Aprilia Wardani yang membahas bagaimana bentuk perawatan diri bagi ibu postpartum dalam mempercepat proses penyembuhan luka (Herlia et al., 2018). Kedua, yaitu karya Ike Mardiati Agustin, Septiyana yang membahas kecemasan pada ibu post partum primipara dengan gangguan proses laktasi (Agustin \& Septiyana, 2018). Adapun persamaan dan perbedaan kajian terdahulu yang ditemukan oleh peneliti adalah sama-sama membahas mengenai ibu primipara, sedangkan kekurangannya yaitu keduanya tidak membahas bagaimana ibu primipara dalam merawat diri selama menjalani periode nifas.

Ibu primipara masih sangat minim pengetahuan dalam hal merawat diri dan bayinya setelah melahirkan, hal ini dikarenakan faktor pengalaman yang sebelumnya belum pernah mereka alami dibanding dengan multipara yang sudah berpengalaman melahirkan lebih dari dua kali. Salah satu masalah yang sering kali membuat ibu primipara masih merasa bingung dan kurang percaya diri yaitu dalam hal merawat diri baik dirinya maupun pada bayinya.

\section{METODE PENELITIAN}

Metodelogi penulisan artikel ini yaitu dengan menggunakan literature review. Database yang digunakan melalui proses pencarian dari Pubmed, Proquest, Ebsco serta Google scholar. Pencarian tersebut dilakukan dengan menggunakan kata kunci pencarian yakni postpartum, penerimaan diri, dan perawatan diri. Tahun penerbitan dalam pencarian jurnal yaitu dari tahun 2017 hingga 2020. Hasil dari telaah artikel jurnal untuk studi literatur ini mendapat 6 artikel dari Pubmed, 4 dari proquest, 4 dari Science Direct serta dari google scholar sejumlah 6. Algoritma pencarian artikel terdapat pada tabel 1 . 
Tabel. 1

Algoritma Pencarian Artikel

\begin{tabular}{|c|c|c|c|}
\hline Pubmed & Proquest & Science Direct & Google Scholar \\
\hline 204 & 589 & 3.190 & 210 \\
\hline
\end{tabular}
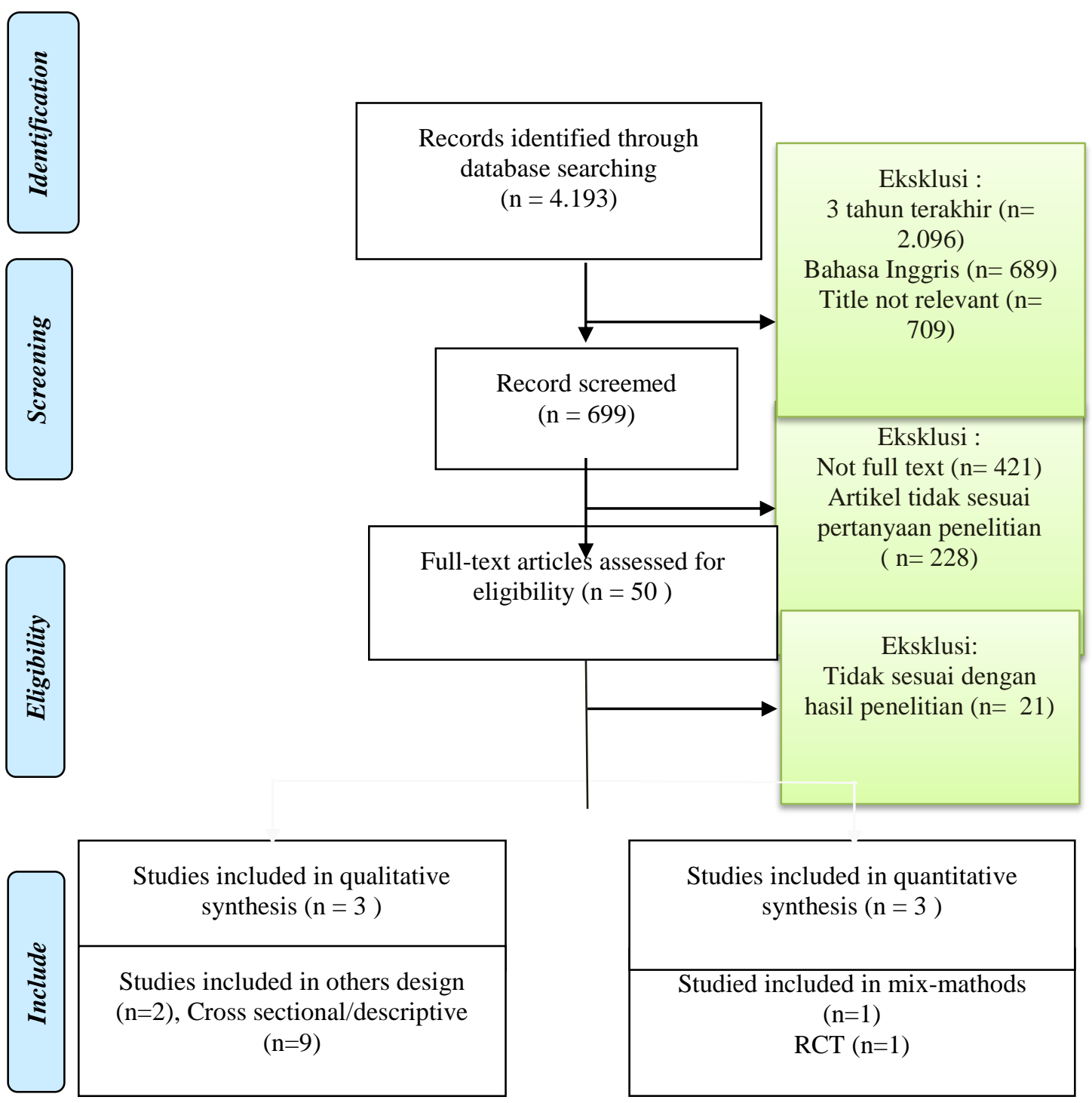

Studies included in quantitative synthesis $(n=3)$

Studied included in mix-mathods $(\mathrm{n}=1)$

$\operatorname{RCT}(\mathrm{n}=1)$

\section{HASIL PENELITIAN}

Tabel. 2

Hasil Literature Review

\begin{tabular}{|c|c|c|c|c|}
\hline No & $\begin{array}{c}\text { Pengarang, Judul, Jenis } \\
\text { Literatur }\end{array}$ & Tahun & Tujuan & Hasil Temuan \\
\hline 1 & $\begin{array}{l}\text { Roets et al., } \\
\text { Strategies to improve } \\
\text { postnatal care in } \\
\text { Kenya: A qualitative } \\
\text { study } \\
\text { Qualitative descriptive } \\
\text { study }\end{array}$ & (2018) & $\begin{array}{l}\text { Penelitian ini } \\
\text { bertujuan untuk } \\
\text { mendeskripsika } \\
\text { n strategi yang } \\
\text { dilakukan untuk } \\
\text { meningkatkan } \\
\text { perawatan ibu } \\
\text { nifas di Kenya }\end{array}$ & $\begin{array}{l}\text { Perawatan diri pasca } \\
\text { melahirkan } \\
\text { merupakan komponen } \\
\text { yang sangat penting } \\
\text { meskipun sering } \\
\text { diabaikan. }\end{array}$ \\
\hline
\end{tabular}




\begin{tabular}{|c|c|c|c|c|}
\hline 2 & $\begin{array}{l}\text { Zhang et al., Analysis } \\
\text { of the effect of } \\
\text { postpartum } \\
\text { rehabilitation nursing } \\
\text { on the management of } \\
\text { the post partum } \\
\text { depression } \\
\text { Qualitative Descriptive } \\
\text { Study }\end{array}$ & 2020 & $\begin{array}{l}\text { Penelitian ini } \\
\text { bertujuan Untuk } \\
\text { mempelajari } \\
\text { pengaruh } \\
\text { rehabilitasi } \\
\text { postpartum } \\
\text { untuk } \\
\text { meredakan ibu } \\
\text { primipara pasca } \\
\text { persalinan. }\end{array}$ & $\begin{array}{l}\text { Ada perubahan } \\
\text { tekanan seperti } \\
\text { perubahan fisiologis } \\
\text { dan psikologis ibu } \\
\text { primipara setelah } \\
\text { melahirkan yang } \\
\text { menjadi faktor } \\
\text { penyebab utama } \\
\text { depresi postpartum } \\
\text { pada ibu primipara. }\end{array}$ \\
\hline 3 & $\begin{array}{l}\text { El-Salam \& Ashour) } \\
\text { Effectiveness of Video } \\
\text { Assisted Teaching } \\
\text { Program on } \\
\text { Postpartum Minor } \\
\text { Discomforts of } \\
\text { Primipara Mothers } \\
\text { Eksperimen Semu }\end{array}$ & 2020 & $\begin{array}{l}\text { Penelitian untuk } \\
\text { mengetahui } \\
\text { efektivitas } \\
\text { program } \\
\text { pengajaran } \\
\text { berbantuan } \\
\text { video terhadap } \\
\text { ketidaknyamana } \\
\text { n ringan } \\
\text { postpartum pada } \\
\text { ibu primipara. }\end{array}$ & $\begin{array}{l}\text { Pada ibu postpartum } \\
\text { primipara mengalami } \\
\text { peningkatan } \\
\text { pengetahuan dan } \\
\text { praktik setelah } \\
\text { menonton video } \\
\text { program pengajaran } \\
\text { berbantuan tentang } \\
\text { ketidaknyamanan } \\
\text { postpartum. }\end{array}$ \\
\hline 4 & $\begin{array}{l}\text { Bakr et al } \\
\text { Women's Knowledge } \\
\text { regarding Postpartum } \\
\text { Warning Signs } \\
\text { Descriptive }\end{array}$ & 2019 & $\begin{array}{l}\text { Penelitian ini } \\
\text { bertujuan untuk } \\
\text { menilai } \\
\text { pengetahuan } \\
\text { wanita } \\
\text { primipara } \\
\text { tentang } \\
\text { peringatan } \\
\text { postpartum. }\end{array}$ & $\begin{array}{l}\text { Perempuan memiliki } \\
\text { pengetahuan yang } \\
\text { salah mengenai } \\
\text { peringatan postpartum } \\
\text { dan memiliki } \\
\text { hubungan signifikan } \\
\text { terhadap postpartum } \\
\text { terutama pada ibu } \\
\text { primipara. }\end{array}$ \\
\hline 5 & $\begin{array}{l}\text { Yousef, } \\
\text { Preparation for } \\
\text { motherhood: Home } \\
\text { based maternal and } \\
\text { newborn care for first } \\
\text { time mothers } \\
\text { A Quasi-Experimental } \\
\text { Design }\end{array}$ & 2019 & $\begin{array}{l}\text { Penelitian } \\
\text { bertujuan untuk } \\
\text { meningkatkan } \\
\text { pengetahuan } \\
\text { dan } \\
\text { keterampilan di } \\
\text { antara ibu yang } \\
\text { baru pertama } \\
\text { kali merawat } \\
\text { diri dan bayinya } \\
\text { selama periode } \\
\text { setelah } \\
\text { melahirkan. }\end{array}$ & $\begin{array}{l}\text { Ibu yang tidak } \\
\text { mempersiapkan diri } \\
\text { dengan baik dapat } \\
\text { dianggap sebagai } \\
\text { kelompok berisiko. } \\
\text { Pendidikan } \\
\text { efektif untuk } \\
\text { meningkatkan } \\
\text { pengetahuan dan } \\
\text { praktek tentang } \\
\text { perawatan ibu dan } \\
\text { bayi baru lahir. }\end{array}$ \\
\hline 6. & $\begin{array}{l}\text { Hussein, } \\
\text { Postpartum Learning } \\
\text { Needs as Perceived by } \\
\text { Mothers at Suez Canal } \\
\text { University Hospital, } \\
\text { Descriptive }\end{array}$ & 2018 & $\begin{array}{l}\text { Untuk } \\
\text { mengenali } \\
\text { kebutuhan } \\
\text { belajar pasca } \\
\text { persalinan } \\
\text { seperti yang } \\
\text { dirasakan oleh } \\
\text { para ibu di } \\
\text { Rumah Sakit } \\
\text { Universitas } \\
\text { Terusan Suez. }\end{array}$ & $\begin{array}{l}\text { Seorang ibu yang baru } \\
\text { melahirkan punya } \\
\text { banyak } \\
\text { kebutuhan belajar } \\
\text { selama masa nifas dan } \\
\text { perawatan. Perlu } \\
\text { adanya penilaian } \\
\text { terhadap kebutuhan } \\
\text { belajar ibu yang harus } \\
\text { didasarkan pada } \\
\text { kebutuhan belajar } \\
\text { perempuan itu sendiri. }\end{array}$ \\
\hline
\end{tabular}




\begin{tabular}{|c|c|c|c|c|}
\hline 7. & $\begin{array}{l}\text { Satyajit \& Sohi } \\
\text { Breastfeeding Secces } \\
\text { in the Early } \\
\text { Postpartum Period and } \\
\text { the Perception of Self- } \\
\text { Efficacy Breastfeeding } \\
\text { and Breast Problems in } \\
\text { the Late Postpartum } \\
\text { Period Among } \\
\text { Primipara Mothers, } \\
\text { Quasy Experimental } \\
\text { Design }\end{array}$ & 2018 & $\begin{array}{l}\text { Penelitian ini } \\
\text { bertujuan untuk } \\
\text { menilai } \\
\text { keberhasilan } \\
\text { menyusui pada } \\
\text { periode } \\
\text { postpartum dan } \\
\text { kemandirian } \\
\text { pada ibu } \\
\text { primipara di } \\
\text { rumah sakit di } \\
\text { Punjab }\end{array}$ & $\begin{array}{l}\text { Terbukti bahwa ibu } \\
\text { primipara yang } \\
\text { berhasil menyusui } \\
\text { dengan baik pada } \\
\text { masa awal nifas } \\
\text { mempunyai persepsi } \\
\text { positif terhadap } \\
\text { kemandirian saat } \\
\text { menyusui. }\end{array}$ \\
\hline 8. & $\begin{array}{l}\text { Fasangharai, } \\
\text { Effects of a maternal } \\
\text { role training program } \\
\text { based on Mercer } \\
\text { theory on maternal self } \\
\text { confidence of } \\
\text { primiparous women } \\
\text { with unplanned } \\
\text { pregnancy, } \\
\text { Qualitatif } \\
\text { Experimental }\end{array}$ & 2019 & $\begin{array}{l}\text { Untuk } \\
\text { mengetahui } \\
\text { pengaruh } \\
\text { program } \\
\text { pelatihan peran } \\
\text { ibu berdasarkan } \\
\text { Teori Mercer } \\
\text { terhadap } \\
\text { kepercayaan diri } \\
\text { ibu primipara. }\end{array}$ & $\begin{array}{l}\text { Program pelatihan ibu } \\
\text { berdasarkan teori } \\
\text { Merder dapat } \\
\text { meningkatkan } \\
\text { kepercayaan diri ibu } \\
\text { primipara. }\end{array}$ \\
\hline 9. & $\begin{array}{l}\text { Salehi et al., } \\
\text { Comparing the Effect } \\
\text { of Talks and } \\
\text { Motivational } \\
\text { Interviews on Self- } \\
\text { efficacy of Exclusive } \\
\text { Maternal Breastfeeding } \\
\text { in Primiparous } \\
\text { Women. } \\
\text { A Randomized } \\
\text { Controlled Clinical } \\
\text { Trial }\end{array}$ & 2019 & $\begin{array}{l}\text { Tujuan } \\
\text { penelitian ini } \\
\text { untuk } \\
\text { membandingkan } \\
\text { pengaruh } \\
\text { pembicaraan } \\
\text { dan wawancara } \\
\text { motivasi } \\
\text { terhadap } \\
\text { kepercayaan diri } \\
\text { pada ibu } \\
\text { primipara. } \\
\end{array}$ & $\begin{array}{l}\text { Dapat simpulkan } \\
\text { bahwa wawancara } \\
\text { motivasi ternyata } \\
\text { lebih efektif dalam } \\
\text { meningkatkan } \\
\text { kepercayaan diri pada } \\
\text { saat menyususi } \\
\text { khususnya pada ibu } \\
\text { primipara pada masa } \\
\text { postpartum. }\end{array}$ \\
\hline 10. & $\begin{array}{l}\text { Bagherinia, } \\
\text { The effect of } \\
\text { educational package on } \\
\text { functional status and } \\
\text { maternal self } \\
\text { confidence of } \\
\text { primiparous women in } \\
\text { postpartum period. } \\
\text { A Randomized } \\
\text { Controlled Trial }\end{array}$ & & $\begin{array}{l}\text { Tujuan } \\
\text { penelitian ini } \\
\text { untuk } \\
\text { mengetahui } \\
\text { pengaruh paket } \\
\text { pelatihan pada } \\
\text { status } \\
\text { fungsional dan } \\
\text { kepercayaan diri } \\
\text { ibu primipara }\end{array}$ & $\begin{array}{l}\text { Dengan didukung } \\
\text { adanya pelatihan } \\
\text { edukasi maternal } \\
\text { mampu meningkatkan } \\
\text { kepercayaan diri ibu } \\
\text { dan perannya menjadi } \\
\text { ibu. }\end{array}$ \\
\hline 11. & $\begin{array}{l}\text { Deborah, } \\
\text { Technology-assisted } \\
\text { nursing for postpartum } \\
\text { support } \\
\text { A Randomized } \\
\text { Controlled Trial }\end{array}$ & 2019 & $\begin{array}{l}\text { Untuk } \\
\text { mengetahui } \\
\text { metode } \\
\text { intervensi } \\
\text { keperawatan } \\
\text { elektronik } \\
\text { efektif dalam } \\
\text { memperbaiki } \\
\text { mood dan } \\
\text { mengurangi } \\
\text { stress ibu } \\
\text { postpartum. }\end{array}$ & $\begin{array}{l}\text { Penerapan intervensi } \\
\text { keperawatan pada } \\
\text { postpartum akan } \\
\text { semakin optimal } \\
\text { hasilnya jika didukung } \\
\text { dengan metode } \\
\text { intervensi berupa } \\
\text { teknologi antara lain } \\
\text { media elektronik dll. }\end{array}$ \\
\hline
\end{tabular}




\begin{tabular}{|c|c|c|c|c|}
\hline 12. & $\begin{array}{l}\text { Ozturk, } \\
\text { Evaluation to } \\
\text { adaptation of } \\
\text { motherhood in } \\
\text { postpartum period } \\
\text { Descriptive Study }\end{array}$ & 2017 & $\begin{array}{l}\text { Untuk } \\
\text { mengetahui } \\
\text { adaptasi } \\
\text { terhadap peran } \\
\text { ibu dan faktor- } \\
\text { faktor yang } \\
\text { berhubungna } \\
\text { dengan adaptasi } \\
\text { peran ibu di } \\
\text { masa nifas. }\end{array}$ & $\begin{array}{l}\text { Adaptasi menuju ke } \\
\text { peran sebagai ibu } \\
\text { dipengaruhi dari segi } \\
\text { sosiodemografi serta } \\
\text { perawatan kesehatan } \\
\text { oleh tenaga kesehatan } \\
\text { karena keterlibatan } \\
\text { mereka lebih kepada } \\
\text { psikososial serta } \\
\text { perawatan fisik ibu. }\end{array}$ \\
\hline 13. & $\begin{array}{l}\text { Fellin \& Yanamura, } \\
\text { Circle by providence : } \\
\text { Supporting discharge } \\
\text { readiness for } \\
\text { postpartum. } \\
\text { Descriptive Study }\end{array}$ & 2020 & $\begin{array}{l}\text { Untuk } \\
\text { memberikan } \\
\text { pendidikan } \\
\text { kesehatan yang } \\
\text { dapat } \\
\text { diandalkan } \\
\text { untuk ibu nifas } \\
\text { agar ibu } \\
\text { menjadi percaya } \\
\text { diri dan mampu } \\
\text { melakukan } \\
\text { perawatan diri. }\end{array}$ & $\begin{array}{l}\text { Media aplikasi untuk } \\
\text { ibu nifas diterima baik } \\
\text { dan terbukti } \\
\text { bermanfaat sebagai } \\
\text { sumber daya dalam } \\
\text { memenuhi kebutuhan } \\
\text { pengetahuan nifas. } \\
\text { Pengaruh media } \\
\text { aplikasi dalam } \\
\text { pemberian edukasi } \\
\text { membuat ibu lebih } \\
\text { percaya diri. }\end{array}$ \\
\hline 14. & $\begin{array}{l}\text { Li et al., } \\
\text { Effect of nursing with } \\
\text { information support } \\
\text { andbehavior } \\
\text { intervention on } \\
\text { location and } \\
\text { breastfeeding success } \\
\text { rate for primiparas. } \\
\text { A Quasi Experimental } \\
\text { Design }\end{array}$ & 2018 & $\begin{array}{l}\text { Untuk } \\
\text { memperbaiki } \\
\text { status menyusui } \\
\text { ibu primipara, } \\
\text { dukungan dan } \\
\text { intervensi } \\
\text { perilaku. }\end{array}$ & $\begin{array}{l}\text { Studi ini } \\
\text { menyimpulkan bahwa } \\
\text { dukungan informasi } \\
\text { dan perlakuan } \\
\text { intervensi dapat secara } \\
\text { efektif meningkatkan } \\
\text { kecemasan dan } \\
\text { depresi, pengetahuan } \\
\text { menyusui, laktasi } \\
\text { pada ibu primipara. }\end{array}$ \\
\hline 15. & $\begin{array}{l}\text { Milani et al., } \\
\text { Postpartum home care } \\
\text { and its effects on } \\
\text { mothers health: A } \\
\text { clinical trial } \\
\text { A Comparative Study }\end{array}$ & 2017 & $\begin{array}{l}\text { Tujuan } \\
\text { penelitian ini } \\
\text { memberikan } \\
\text { perawatan diri } \\
\text { ibu melahirkan } \\
\text { dirumah bagi } \\
\text { para ibu untuk } \\
\text { menilai } \\
\text { pengaruhnya } \\
\text { terhadap } \\
\text { kesehatan ibu. }\end{array}$ & $\begin{array}{l}\text { Studi ini } \\
\text { menyimpulkan bahwa } \\
\text { agar tenaga kesehatan } \\
\text { mempertimbangkan } \\
\text { untuk menyediakan } \\
\text { layanan perawatan diri } \\
\text { di rumah bagi ibu } \\
\text { pada masa nifas untuk } \\
\text { meningkatkan } \\
\text { kesehatan ibu. }\end{array}$ \\
\hline 16. & $\begin{array}{l}\text { Aydemir \& Onan, } \\
\text { Relationship Between } \\
\text { Maternal Self- } \\
\text { Confidence and } \\
\text { Postpartum Depression } \\
\text { in Primipara Mothers: } \\
\text { A follow-Up Study } \\
\text { Quasi-Experimental }\end{array}$ & 2019 & $\begin{array}{l}\text { Penelitian ini } \\
\text { dilakukan untuk } \\
\text { mengetahui } \\
\text { hubungan } \\
\text { kepercayaan diri } \\
\text { ibu dengan } \\
\text { depresi } \\
\text { postpartumpada } \\
\text { ibu primipara } \\
\text { dari waktu ke } \\
\text { waktu. }\end{array}$ & $\begin{array}{l}\text { Kepercayaan diri dan } \\
\text { kecukupan ibu pada } \\
\text { masa perawatan diri } \\
\text { mulai dari postpartum } \\
\text { harus direncanakan } \\
\text { dan diterapkan dengan } \\
\text { baik karena wanita } \\
\text { primipara harus } \\
\text { dibekali dengan } \\
\text { sarana untuk dapat } \\
\text { mengatasi masalah } \\
\text { mereka. }\end{array}$ \\
\hline
\end{tabular}




\begin{tabular}{|c|c|c|c|c|}
\hline 17. & $\begin{array}{l}\text { Gurnita, } \\
\text { Hynotheraphy } \\
\text { Assistance for } \\
\text { Primipara Postpartum } \\
\text { Adaptation } \\
\text { Quasi-Experimental }\end{array}$ & 2019 & $\begin{array}{l}\text { Penelitian ini } \\
\text { dilakukan } \\
\text { dengan tujuan } \\
\text { mengetahui } \\
\text { pengetahuan } \\
\text { dan praktik ibu } \\
\text { primipara dalam } \\
\text { perawatan diri } \\
\text { bayi baru lahir } \\
\text { pada masa nifas. }\end{array}$ & $\begin{array}{l}\text { Penelitian ini } \\
\text { mengungkapkan masa } \\
\text { sensitive ibu } \\
\text { primipara yaitu 1-8 } \\
\text { hari pada masa } \\
\text { postpartum dapat } \\
\text { dihindari dengan } \\
\text { menjadi mandiri } \\
\text { dalam merawat bayi } \\
\text { dengan baik. }\end{array}$ \\
\hline 18. & $\begin{array}{l}\text { Novita \& Elizabeth } \\
\text { Effectiveness of the } \\
\text { Caring-Based Health } \\
\text { Education Program for } \\
\text { Primipara who } \\
\text { Experienced an } \\
\text { Emergency Cesarean } \\
\text { Section in Government } \\
\text { Hospital } \\
\text { Quasi-Experimental }\end{array}$ & 2020 & $\begin{array}{l}\text { Tujuan dari } \\
\text { penelitian ini } \\
\text { adalah untuk } \\
\text { mengurangi rasa } \\
\text { sakit, depresi } \\
\text { dan } \\
\text { meningkatkan } \\
\text { kepercayaan diri } \\
\text { saat menyusui. }\end{array}$ & $\begin{array}{l}\text { Penelitian ini } \\
\text { membuktikan bahwa } \\
\text { penerpan CbHEP } \\
\text { adalah program yang } \\
\text { efektif untuk CoC. }\end{array}$ \\
\hline 19. & $\begin{array}{l}\text { Mathew, } \\
\text { Interventions to } \\
\text { Reduce Postpartum } \\
\text { Fatigue: An Integrative } \\
\text { Reviw of the Literature } \\
\text { Descriptive Study }\end{array}$ & 2018 & $\begin{array}{l}\text { Tujuan dari } \\
\text { tinjauan ini } \\
\text { adalah untuk } \\
\text { meneliti } \\
\text { intervensi dan } \\
\text { strategi yang } \\
\text { digunakan untuk } \\
\text { mengetahui efek } \\
\text { perawatan diri } \\
\text { wanita } \\
\text { primipara pasca } \\
\text { postpartum. }\end{array}$ & $\begin{array}{l}\text { Masa nifas adalah saat } \\
\text { yang penting bagi ibu } \\
\text { primipara dan bayi } \\
\text { baru lahir. Kualitas } \\
\text { strategi perawatan diri } \\
\text { perlu dikembangkan } \\
\text { untuk mengurangi } \\
\text { kelelahan. }\end{array}$ \\
\hline 20. & $\begin{array}{l}\text { Doaa, } \\
\text { Mother's Personel } \\
\text { Care during } \\
\text { Postpartum Period } \\
\text { Descriptive Study }\end{array}$ & 2018 & $\begin{array}{l}\text { Tujuan } \\
\text { penelitian ini } \\
\text { untuk } \\
\text { mengevaluasi } \\
\text { praktik } \\
\text { perawatan ibu } \\
\text { primipara } \\
\text { selama periode } \\
\text { postpartum. } \\
\end{array}$ & $\begin{array}{l}\text { Mayoritas ibu } \\
\text { melakukan perawatan } \\
\text { payudara, melakukan } \\
\text { perawatan perineum } \\
\text { dengan benar, lebih } \\
\text { dari sepertiga ibu } \\
\text { mengalami gizi tidak } \\
\text { sehat selama masa } \\
\text { nifas. }\end{array}$ \\
\hline
\end{tabular}

Ibu primipara cenderung dianggap belum mampu dan berpengalaman dalam mengurus bayi dan melakukan perawatan diri pada masa nifas. Faktor yang dialami ibu primipara mengenai permasalahan ini adalah keterbatasan pengetahuan yaitu akibat dari keterbatasan pengetahuan yang dikuasai sehingga bagi ibu primipara cenderung membutuhkan lebih banyak bantuan. Seorang ibu harus dapat merawat dan menyusui bayinya agar terjamin kebutuhan gizi si bayi. Hal inilah yang menimbulkan kurangnya perawatan diri terhadap ibu primipara, padahal merawat diri bagi seorang ibu merupakan hal yang penting agar tidak menimbulkan gangguan kecemasan kepada ibu primipara. 


\section{PEMBAHASAN}

\section{Personal Hygiene}

Personal hygiene atau memelihara kebersihan diri. Personal hygiene diambil dari bahasa yunani yaitu personal yang mempunyai arti perorangan dan hygiene yang mempunyai arti sehat. Personal hygiene merupakan kegiatan untuk memelihara kebersihan diri bukan hanya membersihkan diri, tetapi juga menggosok gigi dan kebersihan mulut, keramas untuk menjaga kebersihan rambut, kebersihan pakaian, dan kebersihan kaki, kuku, telinga, mata dan hidung (Kurniasari, 2019). Infeksi disebabkan oleh personal hygiene yang kurang baik, oleh karena itu pada masa postpartum seorang ibu sangat penting menjaga kebersihan diri agar tidak rentan terkena infeksi.

Hal tersebut sesuai dengan hasil penelitian Hayati (2020) menyatakan bahwa perawatan diri di rumah untuk ibu primipara yang sesuai dengan teori Merder pada masa postpartum memberikan kontribusi penting terutama kebersihan diri.

\section{Perawatan Perineum}

Perawatan perineum adalah upaya dalam memberikan pemenuhan kebutuhan rasa nyaman dengan cara menyehatkan daerah antara kedua paha yang dibatasi antara lubang dubur dan bagian kelamin luar pada wanita setelah melahirkan agar terhindar dari infeksi bakteri. Perawatan perineum agar tetap bersih pada ibu primipara pada masa nifas sangat penting dilakukan.

Hal tersebut sesuai dengan hasil penelitian yang dilakukan Doaa et al., (2018) menyatakan $86,1 \%$ ibu primipara telah melakukan perawatan perineum dengan benar dan sisanya sebesar $13,9 \%$ ibu primipara masih membutuhkan bantuan untuk melakukan perawatan perenium dengan benar.

\section{Mobilisasi Dini dan Senam Nifas}

Mobilisasi dini didefinisikan sebagai kegiatan bergerak ringan untuk tujuan kesehatan pada periode awal nifas yaitu miring ke kanan-kiri, latihan duduk, latihan berjalan, senam pernafasan, gerakan tumit, latihan dasar panggul, serta sikap postur tubuh yang benar.

Mobilisasi dini pada ibu primipara perlu dilakukan secepat mungkin untuk dapat meningkatkan tonus otot dan aliran darah balik pada bagian kaki dan bagian bawah abdomennya. Senam nifas merupakan senam yang bisa dilakukan sejak hari pertama setelah melahirkan setiap hari sampai dengan hari kesepuluh, terdiri dari beberapa gerakan tubuh guna mempercepat pemulihan keadaan ibu.

Hal tersebut sesuai dengan hasil penelitian yang dilakukan Horie et al., (2017) yang menunjukkan 184 ibu primipara tidak mendapatkan perawatan nifas dirumah dengan baik sehingga kurangnya kepuasan ibu primipara dengan layanan perawatan diri pada masa postpartum.

\section{Perawatan Payudara}

Best care postnatal merupakan proses perawatan payudara pada ibu primipara setelah melahirkan yang bertujuan untuk melancarkan ASI untuk sang bayi. Sebaiknya dilakukan dua kali dalam sehari saat pagi dan sore hari sebelum mandi.

Perawatan payudara pada masa menyusui atau mengasihi bertujuan untuk mempertahankan ASI agar tetap lancar dan mencegah terjadinya bendungan pada saluran ASI, adapun cara yang dapat dilakukan oleh ibu primipara di rumah adalah masase atau pemijatan payudara. Sebagaimana hasil penelitian Doaa et al., (2018) 
menyatakan bahwa 90,6\% ibu primipara telah melakukan perawatan payudara dengan benar dan sisanya sebesar $9,4 \%$ ibu primipara masih membutuhkan bantuan untuk dapat melakukan perawatan payudara dengan benar.

\section{Meningkatkan Kebutuhan Nutrisi}

Kebutuhan nutrisi seharusnya dimulai sejak masa kehamilan untuk menjaga kondisi kesehatan janin dan juga sang ibu. Nutrisi adekuat pada masa kehamilan diperlukan untuk dapat mengurangi resiko komplikasi pada ibu, membantu dalam pertumbuhan jaringan dan meningkatkan berat badan janin secara optimal sehingga bayi dapat lahir secara sehat.

Kebutuhan nutrisi sangat penting selama proses pemulihan pasca melahirkan, kebutuhan nutrisi yang mencukupi dapat memenuhi asupan ASI dan juga mempercepat proses penyembuhan pada ibu primipara. Hasil tersebut sesuai dengan hasil penelitian yang dilakukan Li et al., (2018) menyatakan terdapat hubungan signifikan antara pengetahuan akan nutrisi dan praktik ibu primipara dalam pemberian ASI Eksklusif dan perawatan diri.

\section{Kebutuhan Istirahat dan Tidur}

Ibu yang mengalami kelelahan setelah melahirkan maka harus diberikan kesempatan untuk beristirahat. Ibu harus mengatur istirahatnya seperti saat bayi tidur dengan menggantikan waktu tidur ibu yang hilang saat bayi terbangun malam hari.

Ibu primipara membutuhkan waktu tidur yang cukup selama masa nifas sehingga dapat terjaga kesehatan tubuhnya. Ibu nifas memerlukan waktu istirahat sekitar 8 jam pada malam hari dan 1 jam pada siang hari. Hal ini sesuai dengan hasil temuan penelitian yang dilakukan Doaa et al., (2018) menyatakan ibu memerlukan dukungan perawatan diri dalam mengurangi stress pengasuhan, pendidikan mengenai strategi perawatan diri secara signifikan untuk mengurangi kelelahan pada masa postpartum.

Literature review yang dilakukan mendapatkan hasil 20 jurnal yang dapat dijelaskan menghasilkan beberapa upaya untuk melakukan perawatan diri pada ibu primipara pada masa nifas. Ibu primipara sebagian besar belum mampu melakukan perawatan diri secara mandiri dan belum berpengalaman merawat diri maupun bayinya sehingga cenderung belajar dan berusaha lebih keras menyesuaikan kondisinya pada masa postpartum.

Hal tersebut sejalan dengan hasil penelitian yang dilakukan Gurnita et al., (2018) menyatakan bahwa sebagian besar ibu primipara memiliki pengetahuan yang salah mengenai komponen perawatan diri pada masa postpartum, praktik perawatan diri total ibu primipara dan perawatan bayi baru lahir, dan pengetahuan selama periode postpartum.

\section{Usia}

Usia ibu yang mempunyai anak untuk pertama kali mempengaruhi kondisi bayi dan kesehatan ibu. Hal tersebut dikarenakan ibu dengan usia remaja atau masih muda dan ibu berusia lebih dari 35 tahun beresiko tinggi dalam hal kesehatan saat proses kehamilan dan melahirkan.

Resiko tinggi akan mengikuti ibu dengan usia remaja sehingga akan mengalami perkembangan dan konflik peran yang berhubungan dengan perannya sebagai orang tua (Padila et al., 2021). Hasil penelitian yang dilakukan Yousef (2019) menyatakan dari 
ibu primipara menunjukkan bahwa usia merupakan faktor yang mempunyai kontribusi terhadap kemandirian primipara pada masa nifas.

\section{Tingkat Pendidikan}

Tingkat pendidikan sangat memberikan pengaruh terhadap perilaku seseorang terutama seorang ibu primipara dengan tingkat pendidikan tinggi yang cenderung lebih memperhatikan masalah kesehatan baik kesehatan untuk diri sendiri ataupun untuk keluarganya. Menurut penelitian Hussein et al., (2018) menyatakan bahwa perlu adanya kebutuhan belajar bagi ibu primipara yang harus didasarkan pada kebutuhan belajar perempuan itu sendiri.

Ibu primipara yang memiliki pendidikan rendah juga dapat meningkatkan resiko dua kali kematian perinatal. Selain itu ibu primipara dengan pendidikan tinggi juga biasa mencari informasi yang berkaitan dengan perawatan diri karena mempunyai pemikiran yang lebih terbuka dan rasional.

\section{Budaya}

Adat istiadat yang menjadi faktor penting menentukan perilaku ketika melakukan perawatan diri di rumah. Setiap daerah mempunyai budaya dengan cara-cara yang berbeda dalam melakukan perawatan diri setelah melahirkan. Hal tersebut juga didukung oleh ibu primipara yang akan dibimbing oleh ibu ataupun orang yang lebih berpengalaman dalam keluarganya mengenai cara merawat diri berdasarkan budaya yang ada di lingkungan sekitarnya sehingga membuat ibu primipara menjadi percaya diri karena dukungan keluarga.

\section{Sarana Kesehatan}

Sarana kesehatan yang memadai di masyarakat dapat membantu ibu dalam memberikan informasi yang tepat dalam melakukan perawatan diri. Ibu primipara juga menjadi lebih mudah untuk melakukan pemeriksaan kondisi kesehatan dengan cepat. Sarana kesehatan yang memadai yang terdiri dari berbagai macam dapat digunakan oleh ibu primipara.

Menurut hasil penelitian yang dilakukan Roets et al., (2018) menunjukkan bahwa petugas kesehatan di Kenya berperan penting dalam mendidik dan memberikan pelayanan kesehatan berkaitan dengan ibu nifas. Sehingga sarana kesehatan yang baik dapat berpengaruh juga terhadap perawatan diri yang diperoleh ibu primipara selama masa nifas.

\section{Dukungan Sosial}

Ibu primipara membutuhkan lebih banyak dukungan dan bantuan orang di sekitarnya untuk melakukan perawatan diri pada masa nifas. Dukungan sosial seperti keluarga, teman, atau lingkungan dapat membantu ibu primipara melakukan perawatan diri pada masa nifas. Dukungan sosial berpengaruh menjadi sumber persoalan bagi ibu primipara untuk menentukan perawatan dirinya pada masa nifas.

Beberapa hasil penelitian menunjukkan bahwa dukungan sosial terutama dari keluarga berpengaruh terhadap kejadian postpartum blues bahkan berujung pada depresi postpartum pada ibu usia remaja (Padila et al., 2021). 


\section{SIMPULAN}

Sebagian besar ibu primipara masih kurang mampu melakukan perawatan diri dikarenakan ibu primipara belum berpengalaman merawat diri maupun bayinya, sehingga masih cenderung belajar dan berusaha lebih keras menyesuaikan kondisinya dan faktor-faktor di sekitarnya sangat mempengaruhi ibu primipara untuk melakukan perawatan diri dalam masa nifas. Pengetahuan dan pendidikan ibu primipara sangat mempengaruhi tingkat kemandirian ibu dalam perawatan diri pada masa postpartum.

\section{SARAN}

\section{Saran Teoritis}

Diharapkan bagi peneliti selanjutnya bisa mengembangkan hasil penelitian dengan variabel yang lebih bervariasi dalam upaya meningkatkan perawatan diri ibu primipara pada masa nifas.

\section{Saran Praktik}

\section{Bagi Suami dan Keluarga Terdekat}

Bagi suami dan keluarga terdekat, pemberian dukungan emosional mampu memberikan motivasi agar dapat menyesuaikan dan menerima diri sebagai ibu baru yang berkewajiban untuk mengurus anak-anaknya.

\section{Bagi Ibu Primipara}

Bagi ibu primipara diharapkan mempunyai pengetahuan mengenai kehamilannya terutama pada masa nifas.

\section{DAFTAR PUSTAKA}

Agustin, I. M., \& Septiyana, S. (2018). Kecemasan pada Ibu Post Partum Primipara dengan Gangguan Proses Laktasi. Jurnal Ilmu Keperawatan Jiwa, 1(2), 99. https://doi.org/10.32584/jikj.v1i2.133

Doaa, M., Kamilia, R., Ahmed, R., \& Randa, R. (2018). Mother's Personal Care during Post Partum Period. Egyptian Journal of Health Care, 9(2), 48-60. https://doi.org/10.21608/ejhc.2018.10107

Gurnita, F. W., Suwondo, A., \& Endang, R. S. (2018). Hypnotheraphy Assistance for Primipara Postpartum Adaptation. International Journal of Science and Research (IJSR), https://www.ijsr.net/search_index_results_paperid.php?id=ART2019871

Hayati, F. (2020). Personal Hygiene pada Masa Nifas. Jurnal Abdimas Kesehatan (JAK), 2(1), 4. https://doi.org/10.36565/jak.v2i1.62

Herlia, V., \& Wardani, R. (2018). Hubungan Teknik Vulva Hygiene dengan Penyembuhan Luka Perinium pada Ibu Post Partum. Jurnal Kebidanan, 4(I), 5-10

Horie, S., Nomura, K., Takenoshita, S., Nakagawa, J., Kido, M., \& Sugimoto, M. (2017). A Relationship Between a Level of Hemoglobin after Delivery and Exclusive Breastfeeding Initiation at a Baby Friendly Hospital in Japan. Environmental Health and Preventive Medicine, 22(1), 1-10. https://doi.org/10.1186/s12199-017-0650-7

Hussein, N. A., Shanaby, N. S., \& Abd-Allah, I. M. (2018). Postpartum Learning Needs as Perceived by Mothers at Suez Canal University Hospital. IOSR Journal of Nursing and Health Science (IOSR-JNHS), 7(5), 47-53. http://iosrjournals.org/iosr-jnhs/papers/vol7-issue5/Version-2/H0705024753.pdf 
Indrayanti, I., \& Hikmah, H. (2017). Pemberdayaan Ibu Hamil melalui Perawatan Diri sebagai Upaya Pengurangan Resiko Kematian Maternal di Kecamatan Tretep Kabupaten Temanggung. Prosiding Seminar Nasional Geografi UMS, 728-739

Khatun, F., Lee, T. W., Rani, E., Biswash, G., Raha, P., \& Kim, S. (2018). The Relationships among Postpartum Fatigue, Depressive Mood, Self-care Agency, and Self-care Action of First-time Mothers in Bangladesh. Korean Journal of Women Health Nursing, 24(1), 49. https://doi.org/10.4069/kjwhn.2018.24.1.49

Kurniasari, L. (2019). Analisis Pelaksanaan Pencegahan Komplikasi Nifas di Wilayah Kerja Puskesmas Paal V Kota Jambi Tahun 2018. Scientia Journal, 8(1), 197204. https://doi.org/10.35141/scj.v8i1.436

Li, G., Cong, J., Li, L., \& Li, Y. (2018). Effects of Nursing with Information Support and Behavior Intervention on Lactation and Breastfeeding Success Rate for Primiparas. International Journal of Clinical and Experimental Medicine, 11(3), 2617-2623. http://www.ijcem.com/files/ijcem0070215.pdf

Padila, P., Amin, M., \& Rizki, R. (2018). Pengalaman Ibu dalam Merawat Bayi Preterm yang Pernah dirawat di Ruang Neonatus Intensive Care Unit Kota Bengkulu. Jurnal Keperawatan Silampari, 1(2), 1-16. https://doi.org/10.31539/jks.v1i2.82

Padila, P., Panzilion, P., Juli, A., Nurhayati, N., \& Harsismanto, J. (2021). Pengalaman Ibu Usia Remaja Melahirkan Anak di Masa Pandemi COVID-19. Journal of Telenursing (JOTING), 3(1), 63-72. https://doi.org/https://doi.org/https://doi.org/10.31539/joting.v3i1.2075

Roets, L., Chelagat, D., \& Joubert, A. (2018). Strategies to Improve Postnatal Care in Kenya: A Qualitative Study. International Journal of Africa Nursing Sciences, 9(2018), 62-67. https://doi.org/10.1016/j.ijans.2018.08.003

Wahyuni, N., \& Nurlatifah, L. (2017). Faktor-Faktor yang Mempengaruhi Proses Involusi Uterus pada Masa Nifas di Wilayah Kerja Puskesmas Mandala Kabupaten Lebak Provinsi Banten. Jurnal Medikes, 4(2), 167-176. DOI: 10.36743/medikes.v4i2.83

Yousef, K. F. (2019). Preparation for Motherhood: Home Based Maternal and Newborn Care for First Time Mothers. IOSR Journal of Nursing and Health Science, 8(1), 29-37

Yustiawan, T., \& Nandini, N. (2018). Literasi Informasi Kesehatan Nifas Ibu Hamil Berstatus Sosial Menengah Ke Bawah. Jurnal Administrasi Kesehatan Indonesia, 6(2), 122. https://doi.org/10.20473/jaki.v6i2.2018.122-128 